\title{
Co-Regulated Pendrin and Aquaporin 5 Expression and Trafficking in Type-B Intercalated Cells under Potassium Depletion
}

\author{
Giuseppe Procino ${ }^{a}$ Serena Milano ${ }^{a}$ Grazia Tamma ${ }^{a}$ Silvia Dossenab \\ Claudia Barbieria Maria Celeste Nicolettia Marianna Ranieria Annarita Di Mise ${ }^{a}$ \\ Charity Nofziger $^{b}$ Maria Svelto ${ }^{a, c}$ Markus Paulmichl ${ }^{b}$ Giovanna Valentia,c
}

${ }^{a}$ Dept. of Biosciences Biotechnologies and Biopharmaceutics, University of Bari, Italy; ${ }^{\text {bInstitute of }}$ Pharmacology and Toxicology, Paracelsus Medical University, Salzburg, Austria; 'Centre of Excellence Genomic and Proteomics GEBCA, University of Bari, Italy

\section{Key Words}

Pendrin - Aquaporin - Blood pressure - Hypertension - Acid-base homeostasis - pH • $\mathrm{K}^{+}$depletion

\begin{abstract}
Background: We recently reported that aquaporin 5 (AQP5), a water channel never identified in the kidney before, co-localizes with pendrin at the apical membrane of type-B intercalated cells in the kidney cortex. Since co-expression of AQP5 and pendrin in the apical membrane domain is a common feature of several other epithelia such as cochlear and bronchial epithelial cells, we evaluated here whether this strict membrane association may reflect a co-regulation of the two proteins. To investigate this possibility, we analyzed AQP5 and pendrin expression and trafficking in mice under chronic $\mathrm{K}^{+}$depletion, a condition that results in an increased ability of renal tubule to reabsorb bicarbonate, often leads to metabolic alkalosis and is known to strongly reduce pendrin expression. Methods: Mice were housed in metabolic cages and pair-fed with either a standard laboratory chow or a $\mathrm{K}^{+}$-deficient diet. AQP5 abundance was assessed by western blot in whole kidney homogenates and AQP5 and pendrin were localized by confocal microscopy in kidney sections from those mice. In addition, the short-term effect of changes in external $\mathrm{pH}$ on pendrin trafficking was evaluated by fluorescence resonance energy transfer (FRET) in MDCK cells, and the functional activity of pendrin was tested in the presence and absence of AQP5 in HEK 293 Phoenix cells. Results: Chronic K+ depletion caused a strong reduction in pendrin and AQP5 expression. Moreover, both proteins shifted from the apical cell membrane to an intracellular compartment. An acute $\mathrm{pH}$ shift from 7.4 to 7.0
\end{abstract}


caused pendrin internalization from the plasma membrane. Conversely, a pH shift from 7.4 to 7.8 caused a significant increase in the cell surface expression of pendrin. Finally, pendrin ion transport activity was not affected by co-expression with AQP5. Conclusions: The coregulation of pendrin and AQP5 membrane expression under chronic $\mathrm{K}^{+}$-deficiency indicates that these two molecules could cooperate as an osmosensor to rapidly detect and respond to alterations in luminal fluid osmolality.

Copyright @ 2013 S. Karger AG, Basel

\section{Introduction}

Pendrin is a transport membrane protein acting as an electroneutral anion exchanger for a wide range of anions, such as iodide, chloride, hydroxide, formate, thiocyanate and bicarbonate [1]. Pendrin is expressed in several tissues, such as the thyroid gland [2], inner ear [3, 4] and kidney [5], where it exerts different functions. Pendrin mutations associated with strong impairment or loss of transport function result in an autosomal recessive disease called 'Pendred syndrome', characterized by thyroid and inner ear abnormalities, and non-syndromic hearing loss with an enlarged vestibular aqueduct (ns-EVA).

In the kidney, pendrin is expressed on the apical membrane of type-B intercalated cells in the late distal convoluted tubule (DCT), connecting tubule (CNT) and cortical collecting duct (CCD) and functions mainly as a chloride-bicarbonate exchanger playing a crucial role in acid-base homeostasis [5-7]. Specifically, type-B intercalated cells secrete bicarbonate into urine and express $\mathrm{V}$-type $\mathrm{H}^{+}$-ATPases on the basolateral membrane and pendrin on the luminal membrane.

Although pendrin mutations seem not be associated with kidney abnormalities in patients, it has been suggested that its activity within this organ may play a crucial role in the pathogenesis of hypertension [8]. In line with this hypothesis, pendrin knockout mice become hypotensive under $\mathrm{NaCl}$ restriction [9] and are resistant to aldosterone-induced hypertension [10]. The potential role of pendrin in hypertension is actually associated mainly with its function in chloride reabsorption. In this context, while sodium is considered the major determinant in hypertension, several lines of evidence indicate that an increase in chloride reabsorption can cause extracellular volume expansion and hypertension. Accordingly, it has been shown in humans and in animal models of salt-sensitive hypertension that sodium load without chloride fails to induce a pressor effect [11-14]. More recently, it has been shown that mice overexpressing pendrin in intercalated cells displayed increased renal chloride absorption and developed hypertension when exposed to a high-salt diet [15].

It therefore appears that chloride has a crucial role in triggering hypertension. Type-B intercalated cells represent the only site where chloride can be actively reabsorbed (entry through apical $\mathrm{Cl}^{-} / \mathrm{HCO}_{3}{ }^{-}$exchange via pendrin, and exit from basolateral chloride channels) [5]. Due to these features, pendrin has been proposed as a novel diuretic target [16-18]. In support of this possibility, a recent study showed that double deletion of the $\mathrm{Na}^{+} / \mathrm{Cl}^{-}$ cotransporter (NCC) and pendrin leads to sodium wasting, hypovolemia, and hypotension [19].

The role of pendrin in controlling both acid-base homeostasis and blood pressure implies functional interactions with other proteins. Recently, the water channel aquaporin (AQP) 5 was found to co-localize with pendrin at the apical side of type-B intercalated cells [20]. Interestingly, expression of AQP5 and pendrin in the same cell type is a common feature of several epithelia, such as cochlear $[4,21,22]$ and bronchial epithelial cells [23, 24]. The strict association of pendrin and AQP5 in the apical membrane may indicate that the two proteins are functionally co-regulated. On the other hand, the apparent absence of a basolateral aquaporin in type-B intercalated cells and the low abundance of AQP5 compared 
to AQP2 and AQP3 expressed by principal cells in the same tubule, suggest that AQP5 does not mediate the net transepithelial water reabsorption occurring in the distal tubule. We have previously suggested that AQP5 may instead act as an osmosensor of the luminal hypotonicity produced by the thick ascending limb and distal convoluted tubule. Chloride influx mediated by pendrin might cause increases in cell volume that are promptly 'sensed' due to rapid water entry through AQP5 $[8,20]$. In the aim of evaluating whether AQP5 and pendrin are functionally co-regulated in type-B intercalated cells, we analyzed the expression and trafficking of AQP5 and pendrin in mice under chronic $\mathrm{K}^{+}$depletion, a condition known to cause increased proton secretion often leading to systemic metabolic alkalosis [25]. Under these conditions it has been described that pendrin protein redistributes from the apical membrane to an intracellular compartment, and the relative abundance of pendrin positive cells is strongly reduced [26]. Moreover, besides analyzing modulation of AQP5 and pendrin expression under dietary $\mathrm{K}^{+}$depletion, trafficking of pendrin in response to short-term $\mathrm{pH}$ changes was analyzed in renal Madin-Darby Canine Kidney (MDCK) cells.

\section{Materials and Methods}

\section{Antibodies and reagents}

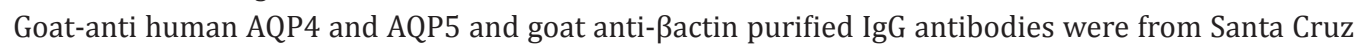
Biotechnology (www.scbt.com). Rabbit polyclonal purified IgG against human AQP2 were produced inhouse as previously described [27]. Anti-pendrin monoclonal antibodies were from MBL® (www.mblintl. com). Mouse monoclonal anti- $\mathrm{Na}^{+} / \mathrm{K}^{+}$-ATPase antibodies ( $\alpha 1$ subunit) were from Millipore (www.millipore. com). Rabbit polyclonal anti Vacuolar type $\mathrm{H}^{+}$-ATPase (V-ATPase) antibodies were kindly provided by Prof. Dennis Brown (Massachusetts General Hospital, Boston, USA). Horseradish peroxidase (HRP)-conjugated secondary antibodies were from Sigma (www.sigmaaldric.com). AlexaFluor $®$-conjugated secondary antibodies for immunofluorescence detection were from Life Technologies (www.lifetechnologies.com). Mice $\mathrm{K}^{+}$-deficient diet (cat.\# C 1037) and control diet (cat.\# C 1000), were purchased from Altronim International (http://www.altromin.com).

\section{Plasmids}

The open reading frame (ORF) of human pendrin from normal thyroid tissue was subcloned by PCR from the pTARGET (Promega Corporation) vector (originally provided by Prof. P. Beck-Peccoz, University of Milan, Italy) into the XhoI and BamHI restriction sites of the pECFPN1 (Clontech) vector. When transfected into mammalian cells, this construct leads to the production of a fusion protein, PDS-ECFP (the enhanced cyano fluorescent protein (ECFP) is fused to the carboxy terminus of pendrin (PDS)), that is suitable for fluorescence resonance energy transfer (FRET) experiments. pEYFP-Mem vector (Clontech) encodes a fusion protein consisting of the amino-terminal 20 amino acids of neuromodulin and the enhanced yellow fluorescent protein (EYFP) (EYFP-Mem). The neuromodulin fragment contains a signal for post-translational palmitoylation. Consequently, transfection of pEYFP-Mem into mammalian cells results in a strong labeling of the plasma membrane. As the exact pendrin structure is still elusive and the location of the amino terminus of the protein is not unequivocally established [28], ECFP was fused to the carboxy terminal domain, whose intracellular location is unanimously accepted. This would allow for FRET detection between ECFP and EYFP, both located in the intracellular environment. In addition, PDS-ECFP presented a better trafficking to the plasma membrane with respect to ECFP-PDS (with ECFP fused to the amino terminus of PDS), which was partially retained in subcellular compartments (Dossena et al., unpublished observations).

For functional tests, the plasmid encoding for EYFP H148Q/I152L (an EYFP mutant with substantially improved sensitivity for iodide [29] and hereafter referred to as EYFP*) was obtained by site-directed mutagenesis of the pEYFPN1 vector (Clontech). Human AQP5 and AQP2 ORFs were engineered into the pCMV6-XL5 (Origene Technologies) and pCB6 $\triangle B H I-h A Q P 2$ plasmids respectively. pCB6 $\Delta$ BHI-hAQP2 was kindly provided by Prof. Deen [30]. All plasmid inserts were sequenced prior to use in experiments (Microsynth AG, Switzerland). 
Procino et al.: Pendrin and AQP5 in Renal Cells

Table 1. Summary of the plasmid construct combinations used in the transfection mixtures for the fluorometric functional test of pendrin (PDS). Numbers indicate the amount of DNA (in $\mu \mathrm{g}$ ) in the transfection mixture for one well of a 96-well plate. See the methods section for further details

\begin{tabular}{lccccccc}
\hline & A & B & C & $\begin{array}{c}\text { D } \\
\text { (control) }\end{array}$ & $\begin{array}{c}\text { E } \\
\text { (control) }\end{array}$ & $\begin{array}{c}\mathrm{F} \\
\text { (control) }\end{array}$ & $\begin{array}{c}\text { G } \\
\text { (background) }\end{array}$ \\
\hline pTARGET PDS & 0.1 & 0.1 & 0.1 & - & - & - & - \\
pCB6 BBHI AQP5 & - & 0.1 & - & - & 0.1 & - & - \\
pCMV6-XL5 AQP2 & - & - & 0.1 & - & - & 0.1 & - \\
pTARGET empty & 0.1 & - & - & 0.2 & 0.1 & 0.1 & 0.3 \\
pEYFP*N1 & 0.1 & 0.1 & 0.1 & 0.1 & 0.1 & 0.1 & - \\
\hline
\end{tabular}

Cell culture and transient transfection

MDCK type I cells (kindly provided by Prof. Deen) were grown in Dulbecco's modified Eagle's medium (DMEM) high glucose, supplemented with $5 \%(\mathrm{v} / \mathrm{v}$ ) fetal bovine serum (FBS), 1\% (v/v) L-glutamine, 1\% $(\mathrm{v} / \mathrm{v})$ non-essential aminoacids and $0.5 \%$ ciprofloxacin.

Human embryonic kidney (HEK) 293 Phoenix cells [31] were cultured in Minimum Essential Eagle Medium (MEM, Sigma, Austria) supplemented with 10\% FBS (Lonza BioWhittaker, Belgium), 2 mM L-glutamine, $100 \mathrm{U} / \mathrm{ml}$ penicillin, $100 \mu \mathrm{g} / \mathrm{ml}$ streptomycin and $1 \mathrm{mM}$ pyruvic acid (sodium salt).

Cells were maintained at $37^{\circ} \mathrm{C}, 5 \% \mathrm{CO}_{2}, 95 \%$ air and $100 \%$ humidity. Subcultures were routinely established every second to third day by seeding the cells into $100 \mathrm{~mm}$ diameter Petri dishes following trypsin/ethylenediaminetetraacetic-acid (EDTA) treatment.

For FRET experiments, MDCK cells were transiently transfected with plasmids $(0.4 \mu \mathrm{g}$ plasmid DNA $\left./ \mathrm{cm}^{2}\right)$ encoding for PDS-ECFP and EYFP-Mem, using lipofectamine $\left(0.75 \mu \mathrm{l} / \mathrm{cm}^{2}\right)$ according to the manufacturer's instructions (Life Technologies, Monza Italy). FRET experiments were performed 48 hours after transfection.

For functional tests (fluorometric method), HEK 293 Phoenix cells were seeded into poly-L-lysinecoated 96-multiwells, grown overnight and transfected with a total amount of $0.3 \mu \mathrm{g}$ plasmid DNA/well by the calcium phosphate co-precipitation method. A summary of the plasmid construct combinations contained in the transfection mixtures for the fluorometric functional tests is reported in Table 1. Specifically, for measuring pendrin-driven iodide influx, cells were co-transfected with $0.1 \mu \mathrm{g}$ of pEYFP* plasmid, $0.1 \mu \mathrm{g}$ of pTARGET plasmid bearing the copy DNA (CDNA) of pendrin, and $0.1 \mu \mathrm{g}$ of the control pTARGET vector (containing no pendrin cDNA) (Table 1, column A). Control cells (with no pendrin expression) were cotransfected with $0.1 \mu \mathrm{g}$ of pEYFP* and $0.2 \mu \mathrm{g}$ of the control pTARGET vectors (Table 1, column D). To assess the possible effect of AQP5 co-expression on pendrin activity, cells were co-transfected with $0.1 \mu \mathrm{g}$ of pEYFP* plasmid, $0.1 \mu \mathrm{g}$ of pTARGET plasmid bearing the cDNA of pendrin, and $0.1 \mu \mathrm{g}$ of pCMV6-XL5 or pCB6 $\triangle \mathrm{BHI}$ vectors bearing the cDNA for AQP5 and AQP2, respectively (Table 1, B and C columns). Control cells (with no pendrin expression) were co-transfected with $0.1 \mu \mathrm{g}$ of pEYFP*, $0.1 \mu \mathrm{g}$ of pCMV6-XL5 AQP5 or pCB6 $\triangle \mathrm{BHI}-\mathrm{hAQP} 2$ and $0.1 \mu \mathrm{g}$ of the control pTARGET vector (Table 1, E and F columns). Functional tests were performed 48 hours post-transfection.

Functional test for measuring pendrin-mediated iodide influx (fluorometric method)

The functional test was performed as already described [32-35], with adaptations allowing the use of a multiplate reader [36, 37]. As a high transfection efficiency is an essential prerequisite, HEK 293 Phoenix cells, in which transfection efficiencies of $\sim 90 \%$ are obtained, are particularly suitable for this approach. In short, cells were washed from the culture medium and bathed in $70 \mu$ of "high chloride" solution (in mM: KCl 2, $\mathrm{NaCl} 135, \mathrm{CaCl}_{2} 1, \mathrm{MgCl}_{2}$ 1, D-glucose 10, 4-(2-hydroxyethyl)-1-piperazineethane sulfonic acid (HEPES) $20,308 \mathrm{mOsm} / \mathrm{Kg}_{\mathrm{H} 2 \mathrm{O}}$ with mannitol, $\mathrm{pH}$ 7.4). After measuring the fluorescence intensity (1 measurement/ sec for $3 \mathrm{sec}$ ), $140 \mu \mathrm{l}$ of "high iodide" solution (in mM: KCl 2, NaI 135, $\mathrm{CaCl}_{2} 1, \mathrm{MgCl}_{2} 1$, D-glucose 10, HEPES $20,308 \mathrm{mOsm} / \mathrm{Kg}_{\text {н20 }}$ with mannitol, $\mathrm{pH} 7.4$ ) were injected into each well. Then, the fluorescence intensity was measured again (1 measurement/sec for $16 \mathrm{sec}$ ). Experiments were performed at room temperature. Fluorescence intensity was detected with the VICTOR ${ }^{\mathrm{TM}}$ X3 Multilabel Plate Reader (Perkin Elmer) equipped with a liquid dispenser and the following filters: excitation: F485 (excitation center wavelength (CWL): 485 
Procino et al.: Pendrin and AQP5 in Renal Cells

nm, bandwidth: $14 \mathrm{~nm}$ ), emission: F535 (emission CWL: $535 \mathrm{~nm}$, bandwidth: $25 \mathrm{~nm}$ ). The fluorescence measured in cells transfected with $0.3 \mu \mathrm{g}$ of the pTARGET vector only (Table 1, column G, background signal) was subtracted from all other fluorescence measurements. Data were expressed as \% fluorescence variations $(\Delta \mathrm{F} \%)$.

Short-term regulation of pendrin cell surface expression by acid-base status: FRET-based imaging

HEK 293 Phoenix cell morphology is scarcely suitable for FRET experiments, where defining the subcellular localization of heterologous proteins is important. Consequently, MDCK cells were used for this purpose. MDCK cells co-transfected with PDS-ECFP and EYFP-Mem were pre-incubated in a buffer containing (in mM): $137 \mathrm{NaCl}, 5.4 \mathrm{KCl}, 0.5 \mathrm{MgCl}_{2}, 1.3 \mathrm{CaCl}_{2}, 4.2 \mathrm{NaHCO}_{3}, 3 \mathrm{Na}_{2} \mathrm{HPO}_{4}, 0.4 \mathrm{KH}_{2} \mathrm{PO}_{4}, 10$ Glucose, 10 HEPES, pH 7.4, and exposed for 20 min to solutions having the same composition but with $\mathrm{pH} 7.0 \mathrm{or} \mathrm{pH}$ 7.8 (obtained by addition of $\mathrm{HCl}$ or $\mathrm{NaOH}$, respectively). Cells were then re-exposed to the $\mathrm{pH} 7.4$ solution for 30 min. FRET signals were monitored and NFRET calculated as previously described [27]. Visualization of ECFP- and/or EYFP-expressing cells and detection of FRET was performed on an inverted microscope (Nikon Eclipse TE2000-S) equipped for single-cell fluorescence measurements and imaging analysis and controlled by MetaMorph/MetaFluor software. Imaging study was performed from ten regions of interest in each cell (near the cell border) and analyzed using MetaMorph and Microsoft Excel software.

\section{Animal studies}

All animal experiments carried out were approved by the Institutional Committee on Research Animal Care in accordance with the Italian Institute of Health Guide for the Care and Use of Laboratory Animals, which conforms to the European Community Directive published in 1986 (86/609/EEC). Wildtype (wt) C57BL/ 6 mice (Harlan Laboratories, males, 25-30 g) were used to obtain kidney samples.

For potassium depletion experiments, animals $(n=6)$ were fed a $\mathrm{K}^{+}$-deficient diet for 14 days; control animals $(\mathrm{n}=6)$ were fed a control diet. Mice were given ad libitum access to food and water and maintained on a 12 hour light/12 hour dark cycle.

Mice were placed into metabolic cages (Tecniplast, www.tecniplast.it). Urine output and osmolality, along with water and food consumption, were monitored daily. Urine osmolality was measured using a vapor pressure osmometer (model 5520; Wescor Inc., www.wescor.com).

At the end of experimentation, mice were anesthetized with tribromoethanol $(250 \mathrm{mg} / \mathrm{kg}$; Sigma Aldrich) and killed by cervical dislocation.

\section{Immunoblotting}

Whole kidneys were isolated from wt C57BL/6 mice and homogenized using a Heidolf tissue homogenizer (http://www.heidolph-instruments.com) at 1,250 rpm in $2 \mathrm{ml}$ RIPA buffer (150 mM NaCl, $10 \mathrm{mM}$ Tris, $0.1 \%$ sodium dodecyl sulphate (SDS), 1\% Triton X-100, 1\% deoxycholate, 5 mM EDTA, pH 7.2) containing protease inhibitors ( $1 \mathrm{mM}$ phenylmethanesulfonyl fluoride, $10 \mu \mathrm{M}$ leupeptin, $1 \mu \mathrm{g} / \mathrm{ml}$ pepstatin, $10 \mathrm{mM}$ NaF, $1 \mathrm{mM}$ sodium orthovanadate, and $15 \mathrm{mM}$ tetrasodium pyrophosphate). Unbroken cells and nuclei were pelleted by centrifugation at $13,000 \times \mathrm{g}$ for $30 \mathrm{~min}$ at $4^{\circ} \mathrm{C} .30 \mu \mathrm{g}$ of proteins in each supernatant were analyzed by Western blotting. Protein samples, diluted in Laemmli's buffer with $50 \mathrm{mM}$ dithiothreitol, were heated for $10 \mathrm{~min}$ at $60^{\circ} \mathrm{C}$, and then resolved on $12 \%$ SDS polyacrylamide gels and electrophoretically transferred to polyvinylidene fluoride membranes (Millipore, Billerica, MA, USA). After blocking with 3\% bovine serum albumin (BSA) in Tris-buffered saline containing 0.05\% Tween 20 (TBS-T), membranes were incubated overnight at $4^{\circ} \mathrm{C}$ with the primary antibodies (anti-AQP5 1:500; anti-AQP2 1:1000; anti-V-ATPase 1:1000; anti-Na $\mathrm{Na}^{+} / \mathrm{K}^{+}$-ATPase 1:10000; anti-actin 1:500). Membranes were washed in TBS-T and incubated with HRP-conjugated secondary antibodies for 1 hour at room temperature. Reactive proteins were revealed with an enhanced chemiluminescent HRP substrate (SuperSignal West Pico Chemiluminescent Substrate, Pierce) and chemiluminescence was detected with the Chemidoc ${ }^{\mathrm{TM} X R S}$ detection system equipped with Image $\mathrm{Lab}^{\mathrm{TM}}$ Software for image acquisition (www.bio-rad.com). Densitometry was performed with ImageJ software (National Institutes of Health, Bethesda, MD, USA). The relative levels of proteins expression were determined by normalizing their individual band intensity to $\beta$-actin band intensity. The band intensity of control animals was set as $100 \%$. 
Immunofluorescence

Mouse kidneys were fixed overnight with $4 \%$ paraformaldehyde at $4{ }^{\circ} \mathrm{C}$, cryopreserved in $30 \%$ sucrose for 24 hours and then embedded in optimal cutting temperature (OCT) medium. Ultra-thin sections (4 $\mu \mathrm{m})$ placed on Superfrost/Plus Microscope Slides (Thermo Scientific, Germany) were subjected to immunofluorescence analysis. Non-specific binding sites were blocked with $1 \%$ BSA in phosphate buffered solution (PBS) (saturation buffer) for $30 \mathrm{~min}$ at room temperature (RT). Sections were then incubated with the primary antibodies for 2 hours at RT in saturation buffer. After washing in PBS, sections were incubated with the appropriate AlexaFluor ${ }^{\mathrm{TM}}$-conjugated secondary antibody (www.lifetechnologies.com) for 1 hour at RT. After washing in PBS, sections were incubated with TO-PRO@-3 Iodide nucleic acid stain (1:10000 in PBS, Life Technologies; excitation/emission wavelengths: 642/661 nm) for $10 \mathrm{~min}$ and finally mounted in PBS/glycerol (1:1) containing 1\% n-propylgallate, $\mathrm{pH}$ 8.0. Confocal images were obtained with a confocal laser-scanning fluorescence microscope (Leica TSC-SP2).

\section{Statistical Analysis}

All data are expressed as arithmetic means \pm S.E.M. For statistical analysis, GraphPad Prism software (version 4.00 for Windows, GraphPad Software, San Diego, California, USA) was used. Significant differences between means were tested by two-tailed Students' t-test or one-way Analysis of Variance (ANOVA) with Bonferroni's post-test, where appropriate. Statistically significant differences were assumed at $\mathrm{p}<0.05$; (n) corresponds to the number of independent measurements.

\section{Results}

$K^{+}$depletion increases urine output and decreases urine osmolality

We previously demonstrated that AQP5 co-localizes with pendrin at the apical plasma membrane of type-B intercalated cells in the CNT/CCD system in mouse, rat and human kidney [20]. In an attempt to identify a possible physiological role for AQP5 in this tract of the nephron, we exploited chronic $\mathrm{K}^{+}$restriction (as a maneuver that decreases pendrin expression and causes the protein to shift from the plasma membrane to the cytosol [26]) and investigated its effect on the expression and subcellular localization of AQP5.

Mice, six per experimental group, were fed $\mathrm{K}^{+}$-deficient or control diet for 14 days. For the entire duration of the experimentation, animals were allocated into metabolic cages, and urinary parameters (output, osmolality and $\mathrm{pH}$ ), along with water intake, food intake and body weight, were measured daily. Figure 1 summarizes the values of the principal physiological parameters tested relative to day zero (before shifting to the $\mathrm{K}^{+}$-deficient diet), day 7 and day 14 . In line with previous findings [38, 39], compared to control diet, $\mathrm{K}^{+}$ depletion significantly increased urine output in all animals tested. In the same group, urine osmolality decreased concomitantly with the increase in urine volume output. Consistent with the polyuria observed in the $\mathrm{K}^{+}$-depleted group, compensatory polydipsia was observed in the same group, resulting in a significant increase in water intake per animal. Urine $\mathrm{pH}$ was significantly increased in all mice during the entire period of $\mathrm{K}^{+}$restriction consistent with a condition of metabolic alkalosis. No significant alteration of food intake or body weight was observed between the experimental and control groups of mice during the 14 days of observation. Together, these data indicate that $\mathrm{K}^{+}$depletion reduces the kidney's ability to concentrate urine.

\section{$H^{+}$-ATPase and AQPs expression under $K^{+}$restriction}

After 14 days of $\mathrm{K}^{+}$restriction, mice were sacrificed and total protein extracts from the whole kidney were analyzed for the expression of the principal water channels and $\mathrm{H}^{+}-$ ATPase, the latter of which is known to be involved in acid-base homeostasis in the kidney. Representative immunoblots and relative densitometric analyses of the immunodetected bands are shown in Figure 2. Compared to control animals, $\mathrm{K}^{+}$depletion had no significant effect on the abundance of $\mathrm{Na}^{+} / \mathrm{K}^{+}$-ATPase in the whole kidney homogenates. Although previous studies have shown an increase in $\mathrm{Na}^{+} / \mathrm{K}^{+}$-ATPase expression after $\mathrm{K}^{+}$depletion 


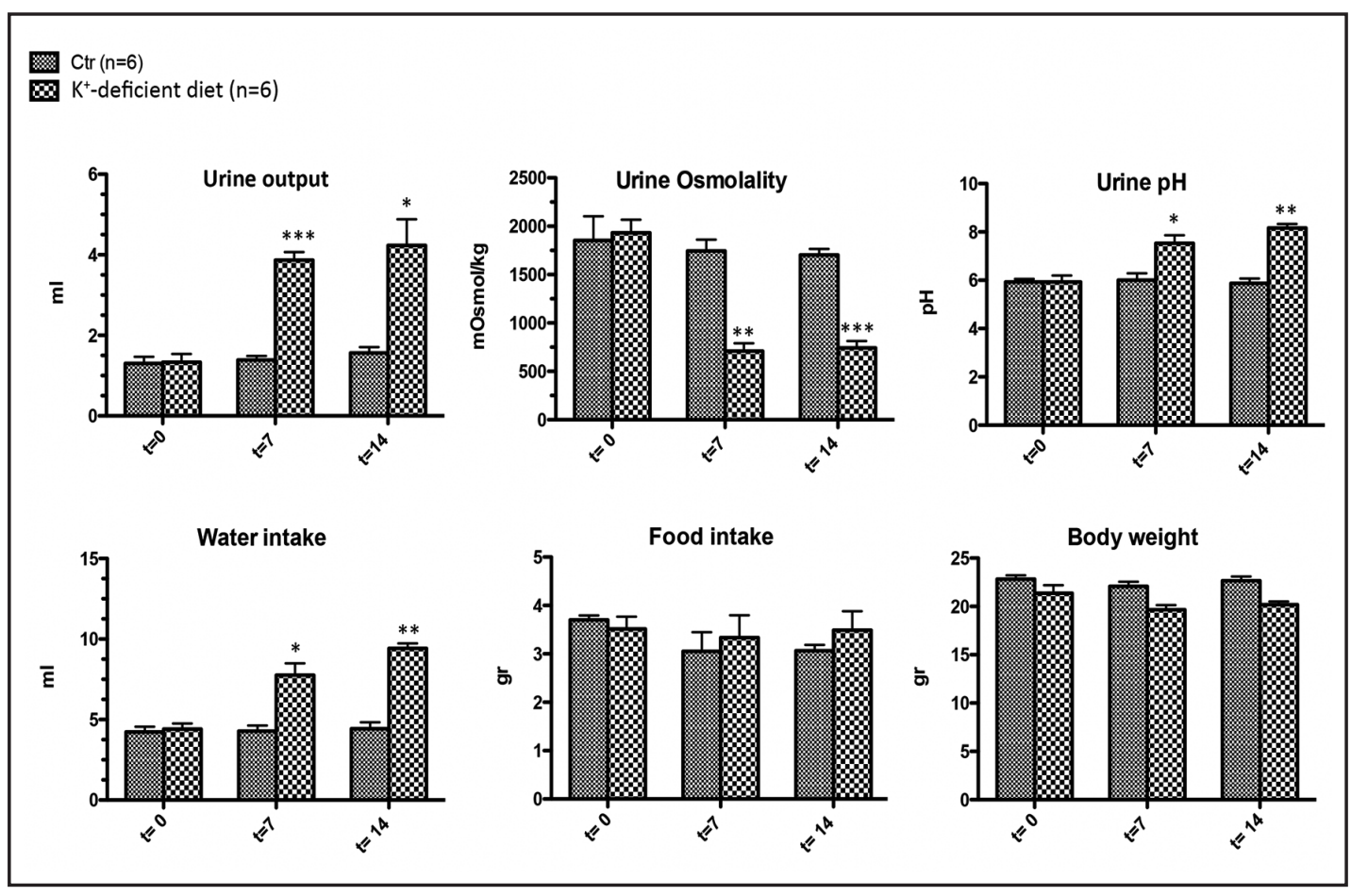

Fig. 1. Effect of $\mathrm{K}^{+}$depletion on physiological parameters in mice. 6 mice were fed a $\mathrm{K}^{+}$-deficient diet and compared with 6 control mice receiving a normal diet for 14 days. Comparison of urinary parameters (output, osmolality and $\mathrm{pH}$ ), along with water intake, food intake and body weight relative to day zero (before shifting to the $\mathrm{K}^{+}$-deficient diet), day 7 and day 14 are given. Data are expressed as means $\pm \mathrm{SE}$ where ${ }^{*} \mathrm{p}<0.05,{ }^{* *} \mathrm{p}<0.005$, and ${ }^{* * *} \mathrm{p}<0.0005$ by Student's t-test for unpaired data.

in the outer medulla $[40,41]$, we cannot exclude that our data obtained in whole kidney homogenates might mask a significant alteration of $\mathrm{Na}^{+} / \mathrm{K}^{+}$-ATPase expression in specific kidney regions. Instead, expression of the $\mathrm{H}^{+}$-ATPase was nearly doubled in mice subjected to $\mathrm{K}^{+}$restriction compared to those fed a control diet. This result is in agreement with previous data obtained in rats [42] showing that chronic $\mathrm{K}^{+}$depletion induces a marked increase in plasma membrane $\mathrm{H}^{+}$-ATPase activity restricted to intercalated cells. This effect may be related to hypokalemic intracellular acidosis, which has been speculated to contribute to the increased insertion of $\mathrm{H}^{+}$-ATPase into the apical membrane [43].

Consistent with the polyuria observed in $\mathrm{K}^{+}$-restricted mice, the abundance of the water channel AQP2 was dramatically reduced in those animals compared to controls (Fig. 2). Accordingly, immunofluorescence analysis of kidney medulla revealed that the expression of AQP2 was strongly reduced in $\mathrm{K}^{+}$-restricted animals compared to control animals, whereas AQP4 expression at the basolateral membrane of the collecting duct cells was not affected by $\mathrm{K}^{+}$-depletion (data not shown). These results confirm previous findings showing that rats fed a low $\mathrm{K}^{+}$diet displayed early polyuria and a urinary concentrating defect associated with a strong decrease in AQP2 expression [39, 44].

AQP5 and Pendrin expression is strongly reduced under $K^{+}$restriction and both proteins display an intracellular localization

Immunoblotting analyses of AQP5 expression in the kidney of control versus $\mathrm{K}^{+}-$ restricted animals (Fig. 2), demonstrated for the first time that AQP5 protein abundance was strongly downregulated after 14 days of $\mathrm{K}^{+}$restriction.

Next, we performed detailed analyses of AQP5 and pendrin subcellular localization in control and $\mathrm{K}^{+}$-restricted animals by immunofluorescence (Fig. 3). In control animals (Fig. 3, 


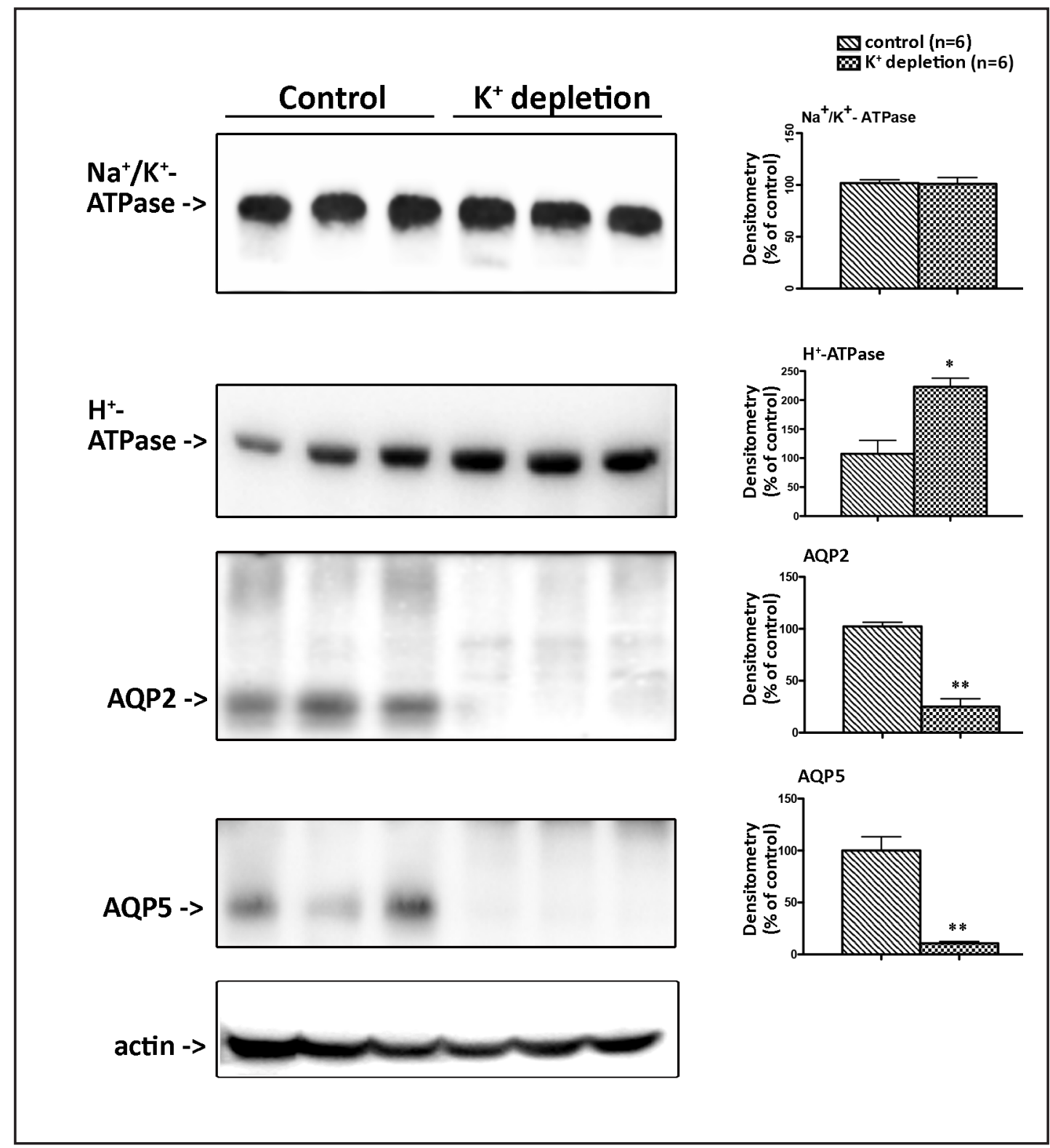

Fig. 2. Effect of $\mathrm{K}^{+}$depletion on the expression of $\mathrm{Na}^{+} / \mathrm{K}^{+}$-ATPase, $\mathrm{H}^{+}$-ATPase, AQP2 and AQP5. Chronic $\mathrm{K}^{+}$depletion for 14 days significantly increased the expression of the $\mathrm{H}^{+}$-ATPase and strongly reduced the expression of AQP2 and AQP5 in kidney homogenates. No change in $\mathrm{Na}^{+} / \mathrm{K}^{+}$-ATPase abundance was observed. Representative immunoblots (left) and relative densitometric analyses of the immunodetected bands (right) are given. Data are expressed as means \pm SE. where ${ }^{*} \mathrm{p}<0.05$ and ${ }^{* *} \mathrm{p}<0.005$ by Student's t-test for unpaired data.

upper panels), AQP5 antibodies decorated the apical membrane of pendrin-positive cells in the kidney cortex, confirming our previous findings [20]. The overlay of the images stained with both antibodies at high magnification (see inset in the right upper corner) indicate an almost complete co-localization between the two proteins. The staining of two antibodies was consistent with the co-expression of the two proteins in the apical membrane of the type-B intercalated cells in the CNT and CCD.

In $\mathrm{K}^{+}$-restricted animals (Fig. 3, $\mathrm{K}^{+}$depletion), AQP5 was dramatically downregulated (as indicated by the decreased number of AQP5-positive cells), which was paralleled with 


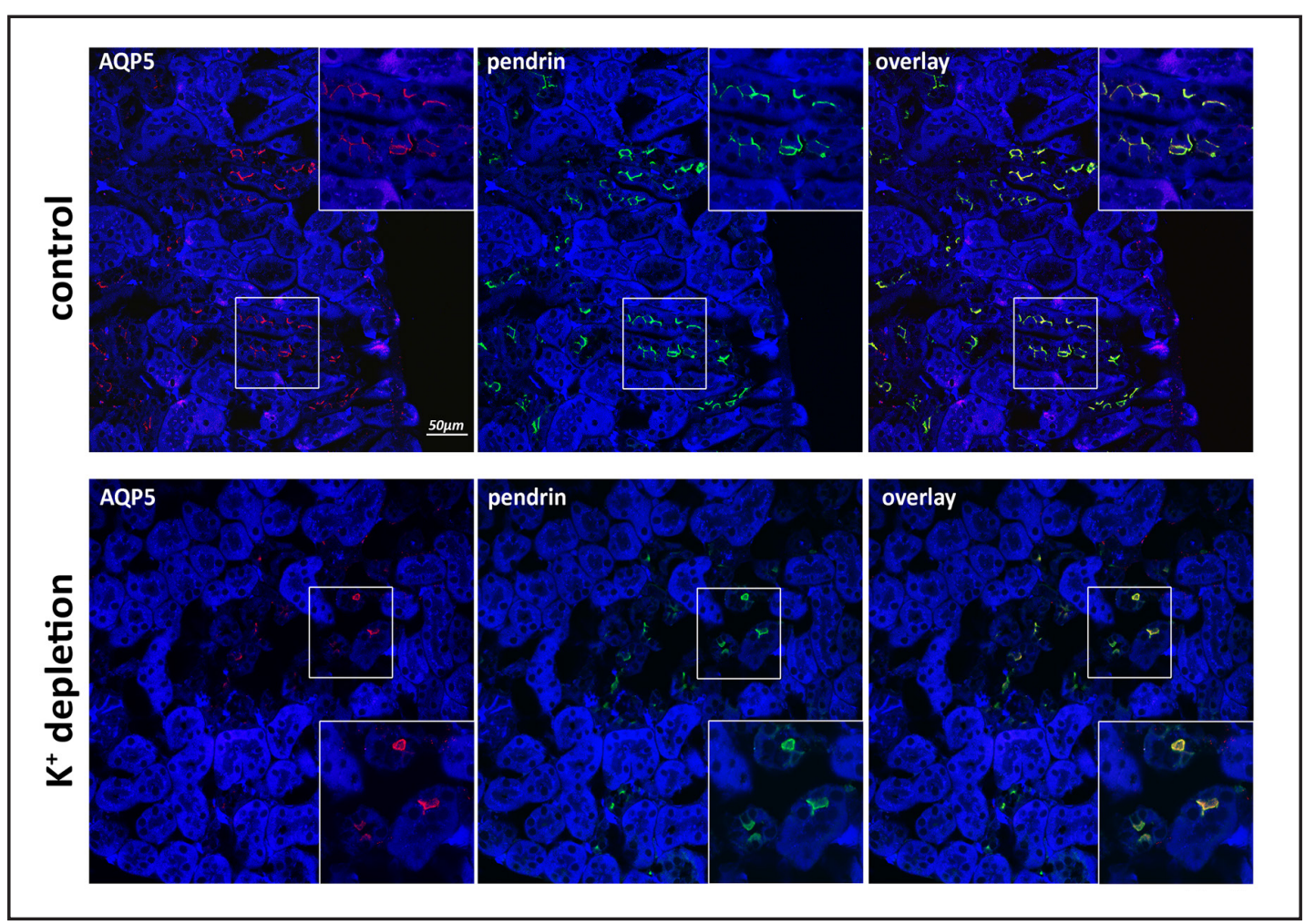

Fig. 3. Effects of $\mathrm{K}^{+}$depletion for 14 days on AQP5 and pendrin localization in the cortical collecting duct of mouse kidney. Under control conditions, AQP5 and pendrin were primarily localized to the apical membrane of type-B intercalated cells. Chronic $\mathrm{K}^{+}$depletion caused a strong reduction in AQP5 and pendrin positive cells and redistribution of the two proteins to an intracellular compartment. Overlay of the two immunostains demonstrates that AQP5 and pendrin co-localize in both experimental conditions.

a strong downregulation in the number of pendrin expressing cells. These results confirm previous reports showing that in chronic $\mathrm{K}^{+}$depletion pendrin protein levels decrease and pendrin expression is shifted to an intracellular pool [26]. A striking consequence of $\mathrm{K}^{+}-$ restricted diet is therefore the strong reduction of pedrin/AQP5 expressing cells. In this respect, recent data in rats fed a $\mathrm{K}^{+}$-deficient diet for 14 days suggest that principal cells and intercalated cells may interconvert in response to changes in dietary $\mathrm{K}^{+}$availability and that autophagic pathways may be involved in the interconversion [45]. This might contribute to the profound change in the expression of both pendrin and AQP5 under our experimental conditions. Interestingly, $\mathrm{K}^{+}$depletion also promoted a marked shift of AQP5 and pendrin from the apical plasma membrane to the sub-apical cytoplasm (Fig. 3, $\mathrm{K}^{+}$depletion). Noteworthy, although both proteins were strongly downregulated and internalized in the kidney tubules of $\mathrm{K}^{+}$-restricted animals, they still co-localize, as shown by the confocal scanning analysis (Fig. 3, $\mathrm{K}^{+}$depletion, overlay).

\section{Short-term trafficking of pendrin in renal cells. FRET-based video imaging}

Altogether, the results illustrated above and obtained by others [26] suggest that chronic $\mathrm{K}^{+}$depletion reduces pendrin expression and causes its internalization to an intracellular compartment. The timing of these effects, however, is unknown. While most of the available in vitro and in vivo data are in fact related to long-term modulation of pendrin expression in response to acid-base homeostasis, little is known about the short-term trafficking of pendrin in response to acute external $\mathrm{pH}$ changes. To investigate this specific point, renal MDCK cells were co-transfected with PDS-ECFP and EYFP-Mem. 24 hours after transfection, cells were exposed for $20 \mathrm{~min}$ to an acidic buffer solution ( $\mathrm{pH} 7.0$ ). Compared to normo-pH 


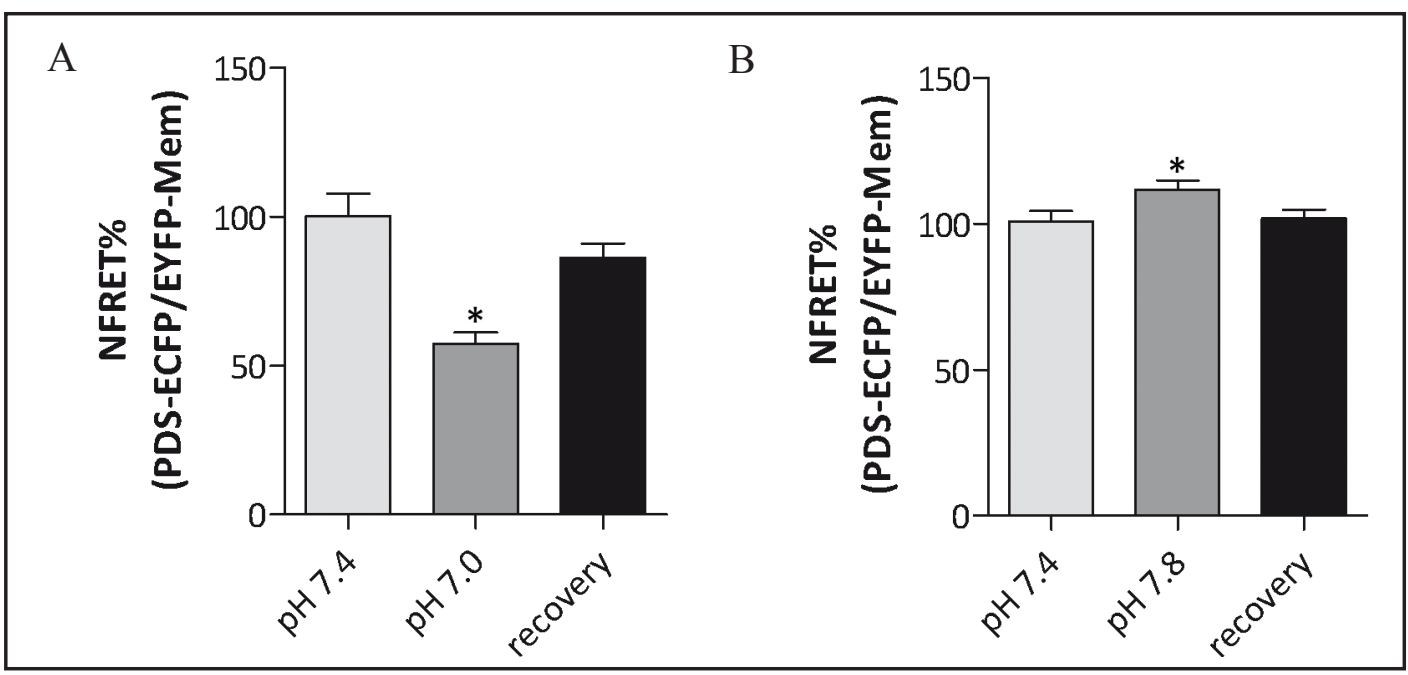

Fig. 4. Trafficking of pendrin in response to acute, external $\mathrm{pH}$ changes. (A) Histograms (means $\pm \mathrm{SE}$; ${ }^{*} \mathrm{p}<$ 0.0001 as indicated by one way Anova Test followed by Newman-Keuls Multiple Comparison test) compare NFRET changes in cells pre-incubated in a pH 7.4 solution, exposed for $20 \mathrm{~min}$ to an acidic solution (pH 7.0) and then re-exposed to a pH 7.4 solution. Acidic external pH caused a significant decrease in pendrin abundance at the plasma membrane. Re-exposure of cells to the $\mathrm{pH} 7.4$ solution reversed the effect on pendrin cell surface expression. (B) Histograms (means \pm SE; ${ }^{*} p<0.05$ as indicated by one way Anova Test followed by Newman-Keuls Multiple Comparison test ) compare NFRET changes in cells pre-incubated in a pH 7.4 solution, exposed for 20 min to a basic solution (pH 7.8) and then re-exposed to a pH 7.4 solution. Basic external pH significantly increased pendrin abundance at the cell membrane. This effect was reversed by re-exposure of cells to $\mathrm{pH} 7.4$.

conditions ( $\mathrm{pH}$ 7.4), treatment with the acidic buffer solution caused a significant decrease in the calculated NFRET values (pH 7.4: $100 \pm 7.55, \mathrm{n}=21$, vs pH 7.0: $57.36 \pm 3.72$, n=45, $\mathrm{p}$ $<0.0001 ; \mathrm{n}$ represents the number of cells) reflecting a decrease in pendrin abundance at the plasma membrane (Fig. 4A). Indeed, this process was reversible since re-exposure of cells to the $\mathrm{pH} 7.4$ solution resulted in an increase in NFRET (recovery: $86.21 \pm 4.72 \mathrm{n}=34$ ). Conversely, when MDCK cells were exposed to a basic buffer solution (pH 7.8), a significant increase in NFRET was observed relative to that detected in normo-pH conditions ( $\mathrm{pH} 7.4$ : $100 \pm 3.45, \mathrm{n}=71$, vs pH 7.8: $111.8 \pm 3.14, \mathrm{n}=64, \mathrm{p}<0.05$; $\mathrm{n}$ represents the number of cells), which is consistent with an increase in pendrin expression at the plasma membrane (Fig. 4B). Re-exposure of cells to pH 7.4 reduced NFRET (Recovery: $101 \pm 3.04, \mathrm{n}=55$ ).

Together, these data strongly suggest that the expression of pendrin at the cell membrane is dynamically sensitive to acute external $\mathrm{pH}$ changes, where low extracellular $\mathrm{pH}$ reduces and high external $\mathrm{pH}$ increases cells surface expression.

Co-expression of pendrin and AQP5 in renal cells does not modify pendrin activity

To evaluate pendrin activity, we measured the EYFP* fluorescence in pendrin overexpressing HEK 293 Phoenix cells before and after addition of iodide to the extracellular solution. Since pendrin can act as a chloride/ iodide $\left(\mathrm{Cl}^{-} / \mathrm{I}^{-}\right)$exchanger $[32,46,47]$, the presence of extracellular iodide should induce a robust iodide flux into the cytoplasm of pendrin-transfected cells. Iodide is a much better quencher of EYFP* fluorescence than chloride [29]. Therefore, an increase in intracellular iodide should lead to a decrease of EYFP* fluorescence. Indeed, as shown in Fig. 1, addition of iodide to the extracellular solution led to a marked decrease $(\Delta \mathrm{F} \%=-63.6 \pm 4.0, \mathrm{n}=24)$ of EYFP* fluorescence in cells expressing pendrin and EYFP*. This value is significantly different from that measured 
Fig. 5. Iodide transport determined in cells transfected with pendrin (PDS) with or without AQP5 or AQP2 co-expression. The intracellular fluorescence intensity was measured in cells transfected with pendrin and EYFP* or EYFP* alone as a control, and with or without AQP5 or AQP2 co-expression. The percentage of fluorescence decrease $(\Delta \mathrm{F} \%)$ induced by the addition of iodide to the extracellular solution was determined over an experimental period of 19 sec. ${ }^{* * *}$ p $<0.001$ compared to the respective control with no pendrin expression as indicated by a one-way ANOVA with Bonferroni's post-test.

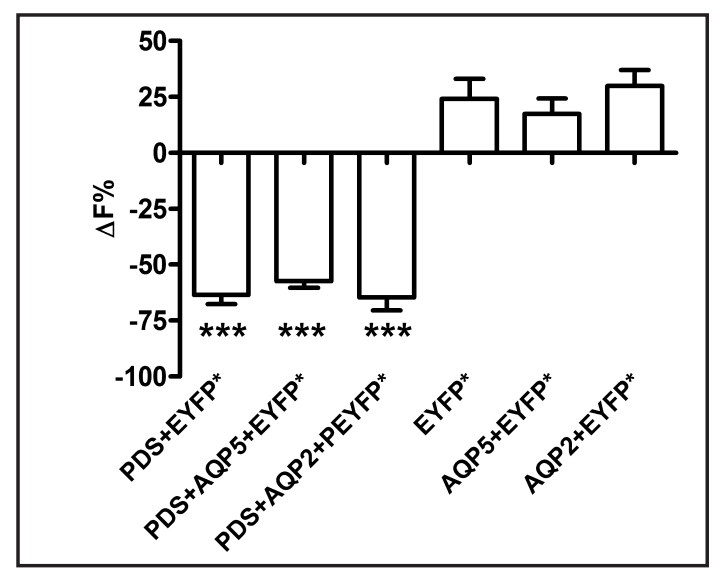

in control cells overexpressing only EYFP*, i.e. $24.0 \pm 9.2, n=24, p<0.001$. These results confirm that pendrin is an iodide transporter $[48,49]$ most likely acting as a $\mathrm{Cl}^{-} / \mathrm{I}^{-}$exchanger in this system [32].

In order to test the possible effect of AQP5 co-expression on pendrin activity, the iodide influx in pendrin-transfected or control cells was measured with or without simultaneous AQP5 or AQP2 expression (Fig. 5). Transfection of cells with pendrin, AQP2 (AQP2 is not expressed in the same cells with pendrin in the kidney, therefore is not expected to directly modify its transport activity) and EYFP* was included in the experimental setting as an additional control. As AQP2 and AQP5 proteins are very similar in size (271 and 265 amino acids, respectively), their expression is expected to equally commit the cell protein synthesis machinery. Addition of iodide to the extracellular solution led to a marked decrease of EYFP* fluorescence in cells co-expressing pendrin, AQP5 and EYFP* $(\Delta \mathrm{F} \%=-57.3 \pm 3.0, \mathrm{n}=24 ; \mathrm{n}$ indicates the number of independent samples collected in 4 experiments) or pendrin, AQP2 and EYFP* $(\triangle \mathrm{F} \%=-64.5 \pm 6.0, \mathrm{n}=24)$. These two values are significantly different from those measured in control cells co-expressing EYFP* and AQP5 $(\Delta \mathrm{F} \%=17.4 \pm 6.9, \mathrm{n}=24$, $\mathrm{p}<0.001)$, or EYFP* and AQP2 $(\Delta \mathrm{F} \%=29.9 \pm 7.2, \mathrm{n}=24, \mathrm{p}<0.001)$, but are not different from each other or from the value corresponding to cells co-expressing pendrin and EYFP*. These results show that co-expression with AQP5 does not modify pendrin activity.

\section{Discussion}

In controlling both acid-base homeostasis and blood pressure, pendrin likely establishes functional interactions with other proteins. Here, we focused our attention on a water channel, AQP5, which was recently identified in type-B intercalated cells [20] and localizes to the apical plasma membrane (similarly to pendrin). AQP5 and pendrin co-localize in the same cells in several tissues and organs, including cochlear [22] and bronchial epithelial cells [23]. Since type-B intercalated cells do not express other AQPs on the basolateral membrane, it is unlikely that AQP5 mediates net transepithelial water flux. Therefore, we suggest that AQP5 and pendrin might both be important to 'sense' the luminal osmolality.

The idea that pendrin or AQP5 can serve as osmosensors has been already suggested for each protein independently. Rodighiero et al. provided evidence that chloride efflux after hypotonicity-induced cell swelling is enhanced in pendrin-overexpressing cells. This would imply that pendrin is activated by hypotonicity [50]. On the other hand, association between AQP5 and transient receptor potential vanilloid 4 (TRPV4) in salivary gland cells exposed to hypotonicity has been shown to control the subsequent regulatory volume decrease [51]. We might speculate that pendrin and AQP5 can cooperate and act as osmosensors to regulate the cell volume of B intercalated cells, which are exposed to luminal hypotonicity produced by the thick ascending limb and distal tubule. 
Parallel AQP5 and pendrin regulation: in vivo evidence in mice under K+ depletion

Dietary $\mathrm{K}^{+}$depletion for two weeks, a treatment already known to cause a strong decrease in pendrin expression and plasma membrane localization in intercalated cells [26], also caused a shift of AQP5 from the apical membrane to the cell interior, which was paralleled by a strong reduction in AQP5 expression (Figs. 2 and 3). These data suggest that in the distal tubule, pendrin and AQP5 might be subjected to a common regulatory pathway.

Since pendrin is an electroneutral exchanger, the driving force for its activity is based exclusively on the concentration gradients of the ions it can transport-namely chloride and bicarbonate $(\mathrm{pH})$ in the B-intercalated cell.

Pendrin has a critical role in the regulation of renal chloride balance [52, 53]. Pendrin has been found to have a relatively high affinity to external chloride also at high $\mathrm{pH}$ value, which can be important to allow bicarbonate secretion in state of alkalosis [54]. Pendrin activity is also regulated by external $\mathrm{pH}$. The effect of external $\mathrm{pH}$ is possibly related to allosteric modifications and represents an intrinsic $\mathrm{pH}$ effect. In vitro experiments in HEK cells demonstrated that sensitivity of pendrin to external $\mathrm{pH}$ depends on its glycosylation state [54]. Specifically, a low external pH stimulates pendrin activity. Since urine is usually relatively acidic, it is likely that the exchanger is constitutively activated under physiological conditions. Instead, in our $\mathrm{K}^{+}$depleted model, the alkaline urine (pH 8.0, Fig. 1) is expected to reduce the activity of the plasma membrane expressed exchanger. The strong reduction in pendrin expression, as well as its internalization observed in the B-intercalated cells of $\mathrm{K}^{+}-$ depleted mice might be due to a fall in intracellular $\mathrm{pH}$ as a result of an increased exchange of $\mathrm{K}^{+}$out of the cell for $\mathrm{H}^{+}$into the cell. In line with these observations, previous studies showed that acidic $\mathrm{pH}$ decreases, whereas alkaline $\mathrm{pH}$ increases pendrin promoter activity in HEK293 cells [55]. Together, these observations support the concept that cellular acidosis leads to pendrin down-regulation that, in turn, participates in determining metabolic alkalosis in the setting of the chronic $\mathrm{K}^{+}$depletion. Besides the importance of $\mathrm{pH}$ in regulating intrinsic pendrin activity and expression, we evaluated in this study whether short-term external $\mathrm{pH}$ changes affects pendrin trafficking.

Our findings using FRET-based imaging demonstrate for the first time that acidification of cell culture medium ( $\mathrm{pH}$ from 7.4 to 7.0) causes a decrease, whereas alkalization causes an increase in cell surface pendrin expression (Fig. 5).

\section{AQP5 and Pendrin interplay: physiological meaning}

The concomitant internalization and decrease of AQP5 expression may reduce water entry in type-B intercalated cells, thereby reducing cell swelling and consequently all the associated responses, such as the release of paracrine signals. ATP release is strongly stimulated by cell swelling and may modulate the function of adjacent principal cells by inhibiting ENaC activity $[8,56]$. A very recent paper clearly demonstrated an intimate and reciprocal functional interaction occurs between type-B intercalated cells and principal cells. In mice deficient in the B1 proton pump subunit (ATP6V1B1) in type-B intercalated cells, the function of principal cells (which normally transport sodium, water, and potassium) is impaired through paracrine ATP signaling triggering PGE2 release originating from type-B intercalated cells [57].

In principle, the presence of pendrin/AQP5 interplay might be an efficient system to avoid further $\mathrm{NaCl}$ reabsorption (in case of increased $\mathrm{NaCl}$ delivery) in the distal nephron through release of paracrine signals. Conversely, in cases where pendrin/AQP5 expression/ activity is reduced, all the responses associated with swelling-induced signaling would be depressed. The signals responsible for reciprocal co-regulation of AQP5 and pendrin are unknown. In this respect, it would be interesting to evaluate whether, in the animal model of pendrin overexpression recently generated by Dominique Eladari and coworkers [15], AQP5 is upregulated as well. In this context, the functional data obtained after co-expression of AQP5 and pendrin in HEK 293 Phoenix cells clearly demonstrate that pendrin activity is not influenced by the presence of the water channel or by other highly permeable water channels, 
like AQP2 (Fig. 5). Therefore is unlikely that the two proteins interact on a molecular level, but possibly are subjected to a common regulatory pathway.

To conclude, we have demonstrated for the first time that dietary $\mathrm{K}^{+}$depletion results in redistribution of AQP5 from the apical membrane to an intracellular compartment, and is associated with an overall reduction of AQP5 expression. These features are very similar to those of pendrin. These data suggest that pendrin and AQP5 expression and trafficking in type-B intercalated cells are likely co-regulated. We suggest that pendrin-mediated $\mathrm{Cl}^{-}$influx coupled to AQP5-dependent water flux leads to cell swelling which might cause the release of paracrine signals. This interplay allows type-B intercalated cells to 'sense' an alteration of luminal ion concentration and to adapt the distal nephron response accordingly.

\section{Conflict of Interests}

The authors have no conflict of interests to declare.

\section{Acknowledgements}

C. Nofziger is supported by the Roche Postdoc Fellowship Program (\#231). This work was further supported by the FWF (P18608) and the FP-7 (PIRSES-GA-2008-230661) grants to M. Paulmichl.

\section{References}

1 Dossena S, Maccagni A, Vezzoli V, Bazzini C, Garavaglia ML, Meyer G, Furst J, Ritter M, Fugazzola L, Persani L, Zorowka P, Storelli C, Beck-Peccoz P, Botta G, Paulmichl M: The expression of wild-type pendrin (SLC26A4) in human embryonic kidney (HEK 293 Phoenix) cells leads to the activation of cationic currents. Eur J Endocrinol 2005;153:693-699.

-2 Royaux IE, Suzuki K, Mori A, Katoh R, Everett LA, Kohn LD, Green ED: Pendrin, the protein encoded by the Pendred syndrome gene (PDS), is an apical porter of iodide in the thyroid and is regulated by thyroglobulin in FRTL-5 cells. Endocrinology 2000;141:839-845.

- Everett LA, Morsli H, Wu DK, Green ED: Expression pattern of the mouse ortholog of the pendred's syndrome gene (Pds) suggests a key role for pendrin in the inner ear. Proc Natl Acad Sci U S A 1999;96:9727-9732.

4 Royaux IE, Belyantseva IA, Wu T, Kachar B, Everett LA, Marcus DC, Green ED: Localization and functional studies of pendrin in the mouse inner ear provide insight about the etiology of deafness in pendred syndrome. J Assoc Res Otolaryngol 2003;4:394-404.

$>5$ Royaux IE, Wall SM, Karniski LP, Everett LA, Suzuki K, Knepper MA, Green ED: Pendrin, encoded by the pendred syndrome gene, resides in the apical region of renal intercalated cells and mediates bicarbonate secretion. Proc Natl Acad Sci U S A 2001;98:4221-4226.

-6 Amlal H, Petrovic S, Xu J, Wang Z, Sun X, Barone S, Soleimani M: Deletion of the anion exchanger Slc26a4 (pendrin) decreases apical $\mathrm{Cl}(-) / \mathrm{HCO} 3(-)$ exchanger activity and impairs bicarbonate secretion in kidney collecting duct. Am J Physiol Cell Physiol 2010;299:C33-41.

7 Wagner CA, Mohebbi N, Capasso G, Geibel JP: The anion exchanger pendrin (SLC26A4) and renal acid-base homeostasis. Cell Physiol Biochem 2011;28:497-504.

8 Hadchouel J, Busst C, Procino G, Valenti G, Chambrey R, Eladari D: Regulation of extracellular fluid volume and blood pressure by pendrin. Cell Physiol Biochem 2011;28:505-512.

-9 Wall SM, Kim YH, Stanley L, Glapion DM, Everett LA, Green ED, Verlander JW: NaCl restriction upregulates renal Slc26a4 through subcellular redistribution: Role in Cl- conservation. Hypertension 2004;44:982-987. 
Procino et al.: Pendrin and AQP5 in Renal Cells

10 Verlander JW, Hassell KA, Royaux IE, Glapion DM, Wang ME, Everett LA, Green ED, Wall SM: Deoxycorticosterone upregulates PDS (Slc26a4) in mouse kidney: Role of pendrin in mineralocorticoidinduced hypertension. Hypertension 2003;42:356-362.

11 Kurtz TW, Al-Bander HA, Morris RC, Jr.: "Salt-sensitive" essential hypertension in men. Is the sodium ion alone important? N Engl J Med 1987;317:1043-1048.

12 Kurtz TW, Morris RC, Jr.: Dietary chloride as a determinant of "sodium-dependent" hypertension. Science 1983;222:1139-1141.

13 Tanaka M, Schmidlin O, Yi SL, Bollen AW, Morris RC Jr: Genetically determined chloride-sensitive hypertension and stroke. Proc Natl Acad Sci U S A 1997;94:14748-14752.

14 Whitescarver SA, Ott CE, Jackson BA, Guthrie GP, Jr., Kotchen TA: Salt-sensitive hypertension: Contribution of chloride. Science 1984;223:1430-1432.

15 Jacques T, Picard N, Miller RL, Riemondy KA, Houillier P, Sohet F, Ramakrishnan SK, Busst CJ, Jayat M, Corniere N, Hassan H, Aronson PS, Hennings JC, Hubner CA, Nelson RD, Chambrey R, Eladari D: Overexpression of pendrin in intercalated cells produces chloride-sensitive hypertension. J Am Soc Nephrol 2013;24:1104-1113.

16 Amlal H, Soleimani M: Pendrin as a novel target for diuretic therapy. Cell Physiol Biochem 2011;28:521526.

17 Denton JS, Pao AC, Maduke M: Novel diuretic targets. Am J Physiol Renal Physiol 2013;305:F931-942. Soleimani M: A novel target for diuretic therapy. Iran J Kidney Dis 2012;6:419-425.

19 Soleimani M, Barone S, Xu J, Shull GE, Siddiqui F, Zahedi K, Amlal H: Double knockout of pendrin and Na-Cl cotransporter (NCC) causes severe salt wasting, volume depletion, and renal failure. Proc Natl Acad Sci U S A 2012;109:13368-13373.

20 Procino G, Mastrofrancesco L, Sallustio F, Costantino V, Barbieri C, Pisani F, Schena FP, Svelto M, Valenti G: AQP5 is expressed in type-B intercalated cells in the collecting duct system of the rat, mouse and human kidney. Cell Physiol Biochem 2011;28:683-692.

21 Wangemann P, Itza EM, Albrecht B, Wu T, Jabba SV, Maganti RJ, Lee JH, Everett LA, Wall SM, Royaux IE, Green ED, Marcus DC: Loss of KCNJ10 protein expression abolishes endocochlear potential and causes deafness in pendred syndrome mouse model. BMC Med 2004;2:30.

22 Mhatre AN, Steinbach S, Hribar K, Hoque AT, Lalwani AK: Identification of aquaporin 5 (AQP5) within the cochlea: cDNA cloning and in situ localization. Biochem Biophys Res Commun 1999;264:157-162.

-23 Krane CM, Fortner CN, Hand AR, McGraw DW, Lorenz JN, Wert SE, Towne JE, Paul RJ, Whitsett JA, Menon AG: Aquaporin 5-deficient mouse lungs are hyperresponsive to cholinergic stimulation. Proc Natl Acad Sci U S A 2001;98:14114-14119.

24 Nakao I, Kanaji S, Ohta S, Matsushita H, Arima K, Yuyama N, Yamaya M, Nakayama K, Kubo H, Watanabe M, Sagara H, Sugiyama K, Tanaka H, Toda S, Hayashi H, Inoue H, Hoshino T, Shiraki A, Inoue M, Suzuki K, Aizawa H, Okinami S, Nagai H, Hasegawa M, Fukuda T, Green ED, Izuhara K: Identification of pendrin as a common mediator for mucus production in bronchial asthma and chronic obstructive pulmonary disease. J Immunol 2008;180:6262-6269.

25 Gennari FJ: Pathophysiology of metabolic alkalosis: A new classification based on the centrality of stimulated collecting duct ion transport. Am J Kidney Dis 2011;58:626-636.

-26 Wagner CA, Finberg KE, Stehberger PA, Lifton RP, Giebisch GH, Aronson PS, Geibel JP: Regulation of the expression of the $\mathrm{Cl}$-/anion exchanger pendrin in mouse kidney by acid-base status. Kidney Int 2002;62:2109-2117.

27 Tamma G, Procino G, Strafino A, Bononi E, Meyer G, Paulmichl M, Formoso V, Svelto M, Valenti G: Hypotonicity induces aquaporin-2 internalization and cytosol-to-membrane translocation of ICln in renal cells. Endocrinology 2007;148:1118-1130.

28 Dossena S, Rodighiero S, Vezzoli V, Nofziger C, Salvioni E, Boccazzi M, Grabmayer E, Botta G, Meyer G, Fugazzola L, Beck-Peccoz P, Paulmichl M: Functional characterization of wild-type and mutated pendrin (SLC26A4), the anion transporter involved in pendred syndrome. J Mol Endocrinol 2009;43:93-103.

29 Galietta LJ, Haggie PM, Verkman AS: Green fluorescent protein-based halide indicators with improved chloride and iodide affinities. FEBS Lett 2001;499:220-224. 
Procino et al.: Pendrin and AQP5 in Renal Cells

30 van Balkom BW, Savelkoul PJ, Markovich D, Hofman E, Nielsen S, van der Sluijs P, Deen PM: The role of putative phosphorylation sites in the targeting and shuttling of the aquaporin-2 water channel. J Biol Chem 2002;277:41473-41479.

31 DiCiommo DP, Duckett A, Burcescu I, Bremner R, Gallie BL: Retinoblastoma protein purification and transduction of retina and retinoblastoma cells using improved alphavirus vectors. Invest Ophthalmol Vis Sci 2004;45:3320-3329.

32 Dossena S, Rodighiero S, Vezzoli V, Bazzini C, Sironi C, Meyer G, Furst J, Ritter M, Garavaglia ML, Fugazzola L, Persani L, Zorowka P, Storelli C, Beck-Peccoz P, Botta G, Paulmichl M: Fast fluorometric method for measuring pendrin (SLC26A4) Cl-/I- transport activity. Cell Physiol Biochem 2006;18:67-74.

33 Dror AA, Politi Y, Shahin H, Lenz DR, Dossena S, Nofziger C, Fuchs H, Hrabe de Angelis M, Paulmichl M, Weiner S, Avraham KB: Calcium oxalate stone formation in the inner ear as a result of an Slc26a4 mutation. J Biol Chem 2010;285:21724-21735.

34 Fugazzola L, Cirello V, Dossena S, Rodighiero S, Muzza M, Castorina P, Lalatta F, Ambrosetti U, Beck-Peccoz P, Botta G, Paulmichl M: High phenotypic intrafamilial variability in patients with pendred syndrome and a novel duplication in the SLC26A4 gene: Clinical characterization and functional studies of the mutated SLC26A4 protein. Eur J Endocrinol 2007;157:331-338.

-35 Pera A, Dossena S, Rodighiero S, Gandia M, Botta G, Meyer G, Moreno F, Nofziger C, Hernandez-Chico C, Paulmichl M: Functional assessment of allelic variants in the SLC26A4 gene involved in pendred syndrome and nonsyndromic eva. Proc Natl Acad Sci U S A 2008;105:18608-18613.

-36 Dossena S, Bizhanova A, Nofziger C, Bernardinelli E, Ramsauer J, Kopp P, Paulmichl M: Identification of allelic variants of pendrin (SLC26A4) with loss and gain of function. Cell Physiol Biochem 2011;28:467476.

-37 Dossena S, Nofziger C, Brownstein Z, Kanaan M, Avraham KB, Paulmichl M: Functional characterization of pendrin mutations found in the Israeli and Palestinian populations. Cell Physiol Biochem 2011;28:477-484.

38 Calcagno L, Durand D, Cella G, Campagnoli M: [Polyuric syndrome due to hypokalemia]. Pathologica 1971;63:291-302.

39 Marples D, Frokiaer J, Dorup J, Knepper MA, Nielsen S: Hypokalemia-induced downregulation of aquaporin-2 water channel expression in rat kidney medulla and cortex. J Clin Invest 1996;97:1960-1968.

40 Buffin-Meyer B, Verbavatz JM, Cheval L, Marsy S, Younes-Ibrahim M, Le Moal C, Doucet A: Regulation of $\mathrm{Na}(+), \mathrm{K}(+)$-ATPase in the rat outer medullary collecting duct during potassium depletion. J Am Soc Nephrol 1998;9:538-550.

41 Hayashi M, Katz AI: The kidney in potassium depletion. I. Na+-K+-ATPase activity and [3H] ouabain binding in MCT. Am J Physiol 1987;252:F437-446.

-42 Silver RB, Breton S, Brown D: Potassium depletion increases proton pump (H(+)-ATPase) activity in intercalated cells of cortical collecting duct. Am J Physiol Renal Physiol 2000;279:F195-202.

43 Bailey MA, Fletcher RM, Woodrow DF, Unwin RJ, Walter SJ: Upregulation of H+-ATPase in the distal nephron during potassium depletion: Structural and functional evidence. Am J Physiol 1998;275:F878-884.

-44 Amlal H, Krane CM, Chen Q, Soleimani M: Early polyuria and urinary concentrating defect in potassium deprivation. Am J Physiol Renal Physiol 2000;279:F655-663.

45 Park EY, Kim WY, Kim YM, Lee JH, Han KH, Weiner ID, Kim J: Proposed mechanism in the change of cellular composition in the outer medullary collecting duct during potassium homeostasis. Histol Histopathol 2012;27:1559-1577.

46 Shcheynikov N, Yang D, Wang Y, Zeng W, Karniski LP, So I, Wall SM, Muallem S: The Slc26a4 transporter functions as an electroneutral Cl-/I-/HCO3- exchanger: Role of Slc26a4 and Slc26a6 in I- and HC03secretion and in regulation of CFTR in the parotid duct. J Physiol 2008;586:3813-3824.

47 Yoshida A, Hisatome I, Taniguchi S, Sasaki N, Yamamoto Y, Miake J, Fukui H, Shimizu H, Okamura T, Okura T, Igawa O, Shigemasa C, Green ED, Kohn LD, Suzuki K: Mechanism of iodide/chloride exchange by pendrin. Endocrinology 2004;145:4301-4308.

48 Gillam MP, Sidhaye AR, Lee EJ, Rutishauser J, Stephan CW, Kopp P: Functional characterization of pendrin in a polarized cell system. Evidence for pendrin-mediated apical iodide efflux. J Biol Chem 2004;279:1300413010. 
49 Scott DA, Wang R, Kreman TM, Sheffield VC, Karniski LP: The pendred syndrome gene encodes a chlorideiodide transport protein. Nat Genet 1999;21:440-443.

50 Rodighiero S, Botta G, Bazzini C, Meyer G: Pendrin overexpression affects cell volume recovery, intracellular $\mathrm{pH}$ and chloride concentration after hypotonicity-induced cell swelling. Cell Physiol Biochem 2011;28:559-570.

51 Da Silva N, Pisitkun T, Belleannee C, Miller LR, Nelson R, Knepper MA, Brown D, Breton S: Proteomic analysis of V-ATPase-rich cells harvested from the kidney and epididymis by fluorescence-activated cell sorting. Am J Physiol Cell Physiol 2010;298:C1326-1342.

-52 Quentin F, Chambrey R, Trinh-Trang-Tan MM, Fysekidis M, Cambillau M, Paillard M, Aronson PS, Eladari $\mathrm{D}$ : The $\mathrm{Cl}$-/HCO3- exchanger pendrin in the rat kidney is regulated in response to chronic alterations in chloride balance. Am J Physiol Renal Physiol 2004;287:F1179-1188.

53 Vallet M, Picard N, Loffing-Cueni D, Fysekidis M, Bloch-Faure M, Deschenes G, Breton S, Meneton P, Loffing J, Aronson PS, Chambrey R, Eladari D: Pendrin regulation in mouse kidney primarily is chloridedependent. J Am Soc Nephrol 2006;17:2153-2163.

54 Azroyan A, Laghmani K, Crambert G, Mordasini D, Doucet A, Edwards A: Regulation of pendrin by pH: Dependence on glycosylation. Biochem J 2011;434:61-72.

55 Adler L, Efrati E, Zelikovic I: Molecular mechanisms of epithelial cell-specific expression and regulation of the human anion exchanger (pendrin) gene. Am J Physiol Cell Physiol 2008;294:C1261-1276.

56 Darby M, Kuzmiski JB, Panenka W, Feighan D, MacVicar BA: ATP released from astrocytes during swelling activates chloride channels. J Neurophysiol 2003;89:1870-1877.

57 Gueutin V, Vallet M, Jayat M, Peti-Peterdi J, Corniere N, Leviel F, Sohet F, Wagner CA, Eladari D, Chambrey R: Renal beta-intercalated cells maintain body fluid and electrolyte balance. J Clin Invest 2013;123:42194231. 